\title{
ACUTE CORONARY SYNDROME
}

Prošireni sažetak / Extended abstract

\section{Is there still a gender gap in patients with ST-elevation myocardial infarction?}

\author{
Martin Marinšek*, Andreja Sinkovič', Nejc Piko², Matevž Privšek² \\ ${ }^{1}$ University Clinical Centre Maribor, Maribor, Slovenia \\ ${ }^{2}$ Medical Faculty, University of Maribor, Maribor, Slovenia
}

Background: A decade ago, women with ST-elevation myocardial infarction (STEMI) were significantly older than men, with more comorbidities, less likely treated by primary percutaneous coronary intervention (PPCl) and their prognosis was worse. The progress in treatment of STEMI patients resulted in an increased survival after STEMI. Our aim was to evaluate and compare possible differences in the treatment and in 30-day and 6-months mortality between the genders in the STEMI patients.

Patients and Methods: We retrospectively evaluated 255 STEMI patients - 187 men and 68 women, admitted in 2012. Reperfusion strategy was PPCl, combined with aspirin and clopidogrel or prasugrel or ticagrelor and a heparin with glycoprotein receptor IIb/IIla antagonist or bivalirudin. We compared baseline clinical data between the genders. We also

\section{Received: $28^{\text {th }}$ Apr 2014}

*Address for correspondence: Department of Medical Intensive Care, University Clinical Centre Maribor, Ljubljanska 5, SI-2000 Maribor, Slovenia.

Phone: +386-40-848613

E-mail: martin.marinsek@guest.arnes.si compared the use and time to PPCl, in-hospital complications, 30-day and 6-month mortality.

Results: The STEMI patients were treated by $\mathrm{PPCl}$ in $92.6 \%$. Their 30-day mortality was $9 \%$ and 6-month mortality was $12.9 \%$. We observed insignificant differences in mean age, comorbidities, the use and time to PPCl, in-hospital complications, discharge treatment, 30-day, and 6-month mortality between the genders. We even observed significantly increased admission troponin I $(10.0 \pm 20.2$, women $3.7 \pm 9.1$ $\mu \mathrm{g} / \mathrm{l}, \mathrm{p}=0.015)$ and peak troponin I levels $(54.4 \pm 38.8$ vs $39.7 \pm 39.2 \mu \mathrm{g} / \mathrm{l}, \mathrm{p}=0.009$ ) in men.

Conclusion: Women account for $1 / 3$ of STEMI population; the gap between the genders in presentation, treatment and outcome in STEMI population is significantly decreasing.

KEYWORDS: gender, gap, ST-elevation, myocardial infarction.

CITATION: Cardiol Croat. 2014;9(5-6):167. 